\title{
Interpreting and exploiting narrative as a sketch design generator for application in VE
}

\author{
Andre Brown ${ }^{1}$, Yisi Liu ${ }^{2}$, Nicholas Webb ${ }^{3}$, Mike Knight ${ }^{4}$ \\ ${ }^{1}$ Wellington School of Architecture, Victoria University of Wellington, New Zealand \\ ${ }^{2}$ School of Architecture, The University of Liverpool, UK ${ }^{3,4}$ School of Architecture, \\ The University of Liverpool, UK \\ landre.brown@vuw.ac.nz²yisi.liu@liverpool.ac.uk \\ 3,4\{njwebb|mknight\}@liverpool.ac.uk
}

\begin{abstract}
The research in this paper focusses on how a narrative text can be the generator of an architectural drawing, or other architectural representation, such as an Architectural Virtual Environment. The drawn physical sketch has traditionally played that role. A particular approach to narrative has been important for some notable architects and their architecture. Ian Ritchie (2014), for instance,

celebrates the use of poetry to describe the essential spirit of a scheme before any drawing is done. The work in the paper here describes the proposition to capture such narrative text in a systematic and structured way. We describe foundational work on how the captured narrative text has been translated into a contemporary, computer-mediated, design development environment. Different narrative accounts recalling a now demolished house form the focus case study. This case study is the vehicle through which the initial principles establishing how best to move from narrative to virtual representation are established and tested.
\end{abstract}

Keywords: virtual environment, narrative, sketch, virtual reality

\section{INTRODUCTION}

In our early work on the digital sketch we undertook research studies that examined the role of the 'sketch' as a re-imagined idea in the developing computer mediated environments of the time. Questions related to how the digital sketch might best replace the conventional physical sketch, and what the appropriate human-computer interface might look like to facilitate productive sketching. We also considered how the sketches were perceived by those from different design and non-design backgrounds (Bassanino and Brown 1999). In later work Brown (2002) considered aspects of digital drawing and representation that examined the idea of visualising the nonvisual in architecture. Consequent to this work we aimed to evaluate the digital sketch and its role in in design development (Hannibal et al. 2004 and 2005).

More closely related to the work in this paper, we have undertaken research on narrative as the definer of a design intention (Webb and Brown 2010). In particular the writing by the French designer Auguste Perret in his treatise on the Ideal Museum was analysed. The analysis of this narrative was the basis for an interrogation of an actual design by Perret. Con- 
sistency of narrative could be checked against the design. This was possible because the narrative was intended as a descriptor of design intent: so it was not a design code, but nevertheless it was meant to provide an idea of what the design outcomes might be.

However in the work here we investigate the narrative where the link between architectural design and that narrative is more loosely framed. Situations where text describes spatial, contextual, and material qualities are taken more as an account rather than as a precise guide.

\section{CONTEXT}

The conventional understanding of the term "architectural sketch" refers to a drawing that represents something. That something can be an interpretation of an actual artefact such as a building, or it can be the external expression of ideas crystallised as lines on paper. In the conventional context this is a manually created artefact that captures mental processes.

In the creative process that brings such physical artefacts about, the space for interpretation is compressed and focussed, as the sketch is being developed into a more developed drawing - the meaning of each line or stroke would be anchored and defined. Its value and meaning might be somewhat captured by the affordances of a manually rendered image on paper; a line overdrawn indicating increased confidence in a design decision, for instance. The process can be taken as an analogy where a person mentally "sketches" out an idea and then finds a valid method to represent it in the physical world. The process that is involved here can be described as a Mental Space Model (Brown and Lee 2000); a process where the creativity happens in the space between 'me and the external expression in the real world'.

If we extend this process to one where a narrative is an instigator of creative thought processes, through the reading experience, the reader becomes immersed in the textual world that she or he explores. The characters may be in a fictional urban context or a remembered real environment. In the fictional the imagination of the context will be conditioned by the plots, interpretation of the clues in the conversations and account of the details of the architectural space. Although not every reader arrives at a common pictorial representation. When the text is adapted to a movie or TV event, the cinematic scene is created and the screenplay process takes place based on the design of the world that the reader has "sketched" mentally. The text creates a mental image of a physical world during the reading process.

The space for interpretation is influenced by how familiar the references in the text are and how many details the text provides to the readers. Readers can become more easily immersed in more familiar texts in which they can concentrate effortlessly (Ryan 2003, p. 96). However, the space for interpretation in a familiar text may be "inversely proportional to the literary power and originality of the reading matter" (Nell 1988, p. 77). It is also true that a difficult text accommodates an extensive range for interpretation. This is especially so when the text does not anchored in a specific time or location; or when the writing style is metaphorical.

Here it is relevant to refer to a design-by-research project regarding the graphic interpretation of Italo Calvino's Invisible Cities, where the focus is on the reader's interpretation of a metaphorical and unfamiliar text of architecture using traditional hand drawing. This requires an importing of "internalised cognitive models, inferential mechanisms, real-life experience, and cultural knowledge, including knowledge derived from other texts" (Ryan 2003, p. 91). Because Calvino's text lacks detailed description of the architectural space, the reader (who has an architectural background and is experienced in sketching) explored the "border" of interpretation: establishing that border before it falls into what Eco calls a "never-ending drift or sliding of meaning" (Eco 1990, p. 151); the key question is 'how far can the reader go?' The final product of the project - an album of drawings of the cities - indicates that the narration acts as a generator of visual representation. Even if we accept that the sketching-out stage is mixed with external information, the workflow sug- 
gests that different readers' interpretations in the form of sketches could be significantly diverse.

Figure 1

Calvino's city of

Pyrrha based on

personal

interpretations.

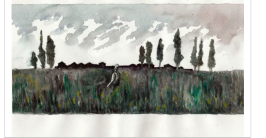

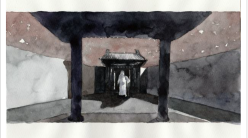

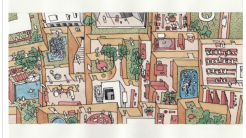

Taking Calvino's city of Pyrrha in the text as an example, it's representation reflects an interpreter's attempts of extending the meaning through the lens of the reader's personal experiences; and this fills a gap between the author's and the reader's understanding. Actual memories inspire the interpreter's representation: a grandfather's last wish to his grandson was to re-experience his home village through a piece of drawing according to his description of that demolished place. Based on the grandfather's description, a fuzzy image of the village gradually emerges from that narration in the grandson's mind, through a mixture of the textual information and some child-like sketches. However, the information in the description is still limited due to the lack of historical documentation and photographs. The interpreter has to interpret the description through the filter of the interpreter's own knowledge, understandings and imagination: "It was one of the many cities where I had never arrived, that I conjured up, through its name" (Calvino 1997, p. 83), see Figure 1. However, the feedback from the family members of the village, also based on imagination as they have never been there either, indicates that the demolished village has multiple parallel interpretations, even if there are common elements. Just as Miller (2002) had described that the textual world had al- ready existed before it was written, people can get a vision beyond the text, but the whole image of the world is unable to be revealed. That is to say, the space for interpretation is always there.

So, as a departure, the research interest in this paper begins to focus on the multiple visual interpretations of a piece of text. This text not being limited to literary works, but extended in the realms of the everyday. As in the case above we take text related to a (real) demolished building as the testing ground for developing a technique to capture narrative in a way that enables a digital representation in an interactive $3 d$ virtual environment.

\section{THE CURRENT INVESTIGATION}

Consequent to the context set out above, the research project described in this paper aims to investigate how a familiar "text" can be interpreted as sketches and how these sketches can be translated to a computer-mediated spatial virtual environment. The meaning of "text" here is extended to include the collective memory in the form of textual descriptions as a narration. This clearly has an important application in heritage architecture. The text may relate to intangible heritage or a memory of what was once tangible.

The particular case study used to establish the basis for future work focuses on a Chinese family's memory relating to a demolished home in which more than four generations used to live. The family members were asked to recall their memories at specific historic times. The responses were collected as text fields in a questionnaire; the questionnaire was developed with the intention to structure the questions in a consistent way to minimise variation in feedback.

The completed questionnaires demonstrate that the narrative text - as memories - motivates the people who do not have an architectural background or sketching experience to express the details graphically through memory. Moreover, the extended meaning of sketching as narrative is captured in the resulting outcomes. These captured text fields show 


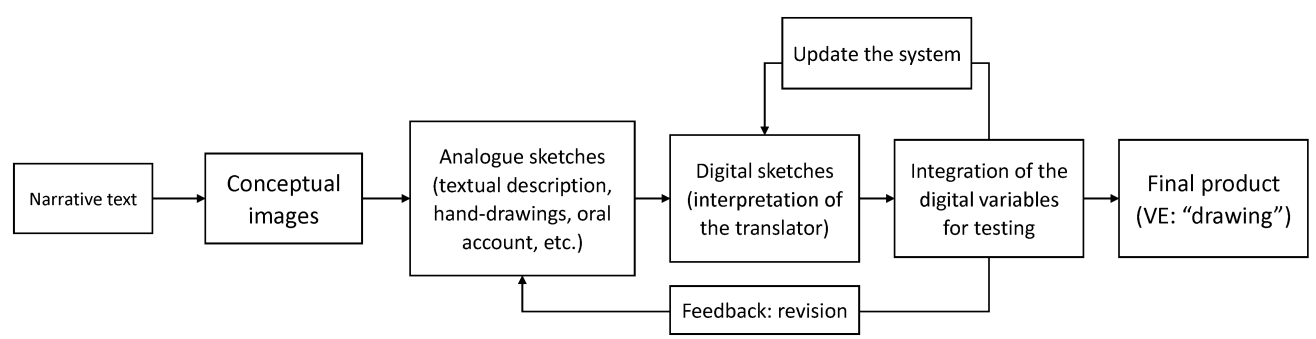

that data can be derived that is translatable; translatable into qualities such as such as architectural form, spatial sequences, sense of scale and dimensions, materials, aural and emotional experiences. But the narrative does this in a way that narrows the space for interpretation. In other words, There is the analogy the "sketch" being developed to become the "drawing" stage. , to describe the process of translation from the conceptual interpretation of a text to a digital representation. The process in shown in Figure 2.

The translation of the data in the questionnaire is taken as the interpretation of the translator. The proportion of the translator's re-creation or attempt to fill the gap depends on how many details the subjects can provide. For example, the width of a door or the height of the ceiling can be reflected literally in a digitally created environment. However, a description such as "it was a gloomy alley," or "there was a 1980sstyle-wardrobe" needs the translator's interpretation. Therefore, the original "sketchers" - the family members - would come back to experience the VE. Their feedback reflects that to what extent the digital representation successfully re-creates the quality of the conceptual accounts.

The conclusion arising from our work is that the conventional sketch as a tool, bridges the imaginative involvement in a narrative text and the digital representation. A resulting workflow integrates the immersion in the text, sketching out the imaginary architecture and re-interpretation of the sketches. The workflow can be examined by the reader to test whether the reading experience can successfully re- emerge in the VR experience.

\section{CASE STUDY TO ESTABLISH THE PROCESS AND WORKFLOW}

This section describes the process that has been devised and modified to enable the analysis and codification of narrative text. It is the foundation work through which the techniques adopted for a larger study could be tested. The particular task set is the digital re-construction of a demolished home based on collective memory of a small group who occupied the space in the past.
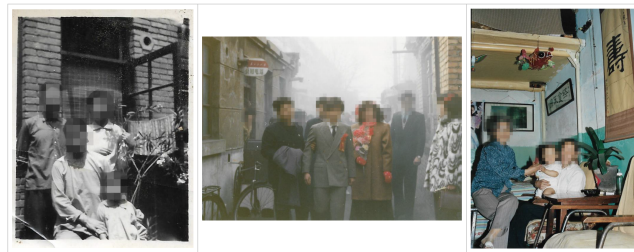

\section{Case Study Introduction}

This section introduces the origin of the case study giving a brief history of the demolished home. The family members used to live there for decades until it was demolished as a casualty of city regeneration that was undertaken during the second half of the 1990s (see Figure 3). The family members moved to a newer multi-storey building, but they still often recalled the lost moments in detail: the refurbishment and collapse of the buildings, the furnishing in dif-
Figure 2

Case study

workflow
Figure 3

Left: the family in 1970s (first, second and third generations); middle: a wedding in 1980s (third generation); right: a photo of the interior space in 1990s (second and fourth generations). 
Figure 4

Textual descriptions as the original

"narration." Left:

Participant 03;

middle: participant

06; right:

participant 11. ferent periods and the stories that took place in the building.

This smaller project was intended as a pilot for an examination of narrative related to a larger urban landscape. The collective memory which reflects the memory of a city may inform the research to investigate how we can use VR to re-experience a city in a specific period in terms of not only the representation of the architecture, but also the impact of the emotions and multi-sensory experiences.

\section{Case Study Method}

Because this case study is to rebuild a part a city house based on the memories from those who do not have an architectural background, it is essential to validate a clear workflow to let the family members engage into the project and describe their memories in simple ways. Moreover, as opposed to a general interview or conversation, since the memories are to be translated to a digital version, the description must be stored and categorised as 'data' which is as consistent as possible and hence translatable.

Initial results from the family members suggested that their memories are overlain and contradictory in some ways. Despite the inconsistency the initial work established that the content of personal memory could be categorised as visual, aural, olfactory and haptic. This suggested that using a questionnaire to collect their description of the memory systematically is feasible and would be best structured along these themes. As a result, the family members were invited to recall and describe their memory within the questionnaire so that the following stages of the research could translate the text into digital form.

However, the respondents were not limited to writing. The result of the questionnaires shows that some of the family members spontaneously use sketches to describe their memory rather than using pure textual description, even though they are not mature sketchers. This is a sign that the memory invokes the motivation of drawing to push the interpretation from text to visual form. More importantly, the sketches could be taken as more valid translatable data than the textual description because the reinterpretation of text data can be less precise to some extent.

The next stage the workflow uses Unity3D as the primary tool to translate and reassemble the categorised memories to form a VR environment in which the users can interact with the system to reexperience the demolished home in a chronological order. The system was presented to the family members and feedback was collected from them, which was then employed to update and refine the system.

This case study describes an informal interview with the family members in order to have an initial perspective of the structure of the memory and test the potential workflow that had been conceived. It indicates that the family members' description could easily slip into a disordered conversation, even an argument because they tried to correct the different descriptions of the same aspect where their memories diverged. However, it was clear that using a systematic and structured questionnaire could make this less problematic for the participants to fill in their memories.
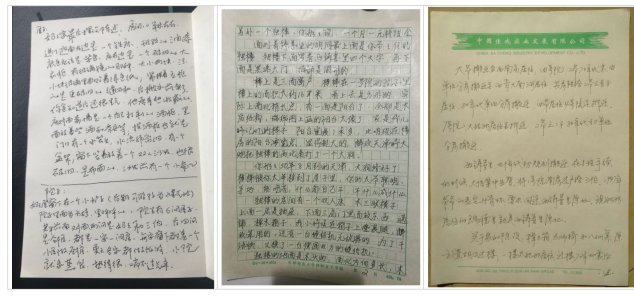

\section{Participation Design}

Because the family members do not have an architectural background, it is essential to lead them to explain their memory in a way that the descriptions can be categorised in architectural terms. Other researchers such as Coughlan and Johnson (2006) note the importance of minimising ambiguity and misunderstanding when translating language-enabled processes to computationally-enabled ones. They 
describe the importance of establishing a 'common language'.

The case study described here has a particular function of establishing an appropriate questionnaire to be used to collect descriptions. The resulting records fall into three structured parts, with 18 questions regarding the textual description as the original "narration" (see Figure 4), and covered the level of experience, scenario and environment and spatial cognition. To offer a reference by which the participants can start recalling from specific moments and associate them to the architectural space, the questionnaire included several photographs showing different periods of the home. Then the family members answer the following questions regarding architectural elements as well as intangible memories such as sound, atmosphere, and emotions.

\section{Case Study Results and Findings}

The next stage in the process is the analysis of the "text" - the family members' narrative descriptions. The responses are categorised regarding the different sensory experiences such as visual, aural, olfactory, haptic and emotions.

With the prompt of previous photos, the results show that the family members have not only recreated the space shown in the photos but also revealed more information which cannot be seen in the photos. Every piece of the object has its meaning and background history, which is not always evident from its appearance. The left hand row of Table 1 shows an example of a family member describing a memory and how the text is deconstructed to types of information, which are highlighted in different colours in the textual description, and sorted into the categories of visual (green), aural (blue), haptic (yellow), olfactory (red) and emotions (purple) in the right hand row.

\begin{tabular}{|c|l|}
\hline $\begin{array}{c}\text { Type of items in } \\
\text { the questionnaires }\end{array}$ & \multicolumn{1}{c|}{ Content } \\
\hline Visual & $\begin{array}{l}\text { Old walls and stained bricks } \\
\text { A threshold of the gate and rock gate pier } \\
\text { Wooden gate } \\
\text { Remains of couplets } \\
\text { A narrow view of the courtyard } \\
\text { Sundries beyond the entrance } \\
\text { Unknown pillar adjacent to the gate } \\
\text { Snow on the ground }\end{array}$ \\
\hline Aural & $\begin{array}{l}\text { The noise of firecrackers } \\
\text { Laughter everywhere } \\
\text { The sound of speaking }\end{array}$ \\
\hline Haptic & $\begin{array}{l}\text { The rough surface of the bricks } \\
\text { The smooth edge of every piece of furniture }\end{array}$ \\
\hline Olfactory & $\begin{array}{l}\text { The intense smell of smoke } \\
\text { The inviting aroma of the dishes }\end{array}$ \\
\hline \multirow{5}{*}{ Emotions } & $\begin{array}{l}\text { Trowded, dark, calm and shabby } \\
\text { Everything looks huge and scary } \\
\text { Enjoy, exciting } \\
\text { Could not help to sneak into the alley to catch a }\end{array}$ \\
\hline & \begin{tabular}{l} 
glance \\
\hline
\end{tabular} \\
\hline
\end{tabular}

Table 1

Categorised elements based on a family members' description. 
Table 2

Translation from the collected information to its implementation.

Figure 5

Sketches from three participants: a. Participant 6, the profession of this person was an engineering draftsperson; $b$. Participant 2, who is now an auditor; $C$. Participant 8, who works in real-estate development.
The resulting table of categorised elements forms a library from which the information is derived, to be re-integrated into the VR system to test how successfully it can generate the same (or similar) experience again to the users. In the translation stage, the elements need to find their correspondence in a VR representation, which will be discussed in a later section.

Moreover, the results of the questionnaire show that the answers were adequately recorded and categorised into different sections, and responses to the same question by various participants were also documented. Although the questionnaire does not require the participants to answer the questions with graphics, as noted above, some sketches can be found in their responses. In general, the sketches represent architectural layouts such as a plan of a building or a room, or a site plan with annotations. Although the participants do not have any architectural background, the questionnaire motivated them to translate the image in memory to graphic forms with abundant details spontaneously, in addition to text. Furthermore, one might say that the sketches often reflect the participants' professions to some extent, see Figure 5.

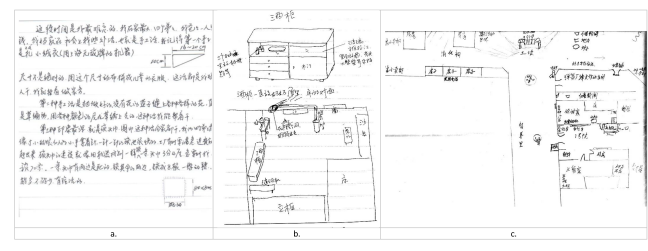

\section{VR Build}

The study utilises SketchUp to create digital models of the collected data and Unity3D for interactive VR. As a final product, the results of the questionnaire are to be integrated as a game programme.

As is mentioned previously, the categorised elements have to find their correspondence in the system so as to be re-created and be re-experienced by the users. According to Table 1, different categories of the content can be translated as a variety of digital representations. The relationship between the analogue description and the digital translation is presented in Table 2. Elements such as locomotion type, interaction type and user interface (UI) are essential in VR but absent in the descriptions collected, and therefore also need to be clarified in the system. Table 2 shows how the type, content, digital translation, and software employed are linked.

\begin{tabular}{|c|c|c|c|c|}
\hline & $\begin{array}{c}\text { Type of } \\
\text { description }\end{array}$ & Content of the description & Digital translation & Software \\
\hline \multirow{5}{*}{ 1) } & \multirow{5}{*}{ Visual } & $\begin{array}{l}\text { The entity of objects, } \\
\text { including architecture with } \\
\text { details, infrastructure, } \\
\text { interior objects, etc. }\end{array}$ & $\begin{array}{l}\text { Full-scale digital models, } \\
\text { with embedded material }\end{array}$ & $\begin{array}{l}\text { SketchUp, } \\
\text { Rhinoceros, } \\
\text { Unity3D }\end{array}$ \\
\hline & & $\begin{array}{l}\text { Natural objects - plants, } \\
\text { mountain, rocks, terrain, } \\
\text { water, etc. }\end{array}$ & Digital models & Unity3D \\
\hline & & Material, texture of the object & $\begin{array}{l}\text { Texture, Material, shader } \\
\text { system }\end{array}$ & Unity3D \\
\hline & & Weather & $\begin{array}{l}\text { HDR (High Dynamic Range } \\
\text { imaging) skybox, particle } \\
\text { system }\end{array}$ & Unity3D \\
\hline & & Artificial light & Lighting system & Unity3D \\
\hline 2) & Aural & A variety of sounds & A mixture of audio system & Unity3D \\
\hline \multirow{2}{*}{ 3) } & \multirow{2}{*}{ Haptic } & $\begin{array}{l}\text { The collision (avoid walking } \\
\text { through the object) }\end{array}$ & Collision system (rigid body) & Unity3D \\
\hline & & $\begin{array}{l}\text { Haptic feeling on the object's } \\
\text { surface }\end{array}$ & An embodiment in reality? & $N / A$ \\
\hline 4) & Olfactory & The mixed smell & $\begin{array}{l}\text { An installation or a room to } \\
\text { ventilate the imitated smell? }\end{array}$ & $\begin{array}{l}\text { HTC Vive } \\
\text { and external } \\
\text { installation }\end{array}$ \\
\hline 5) & Locomotion & $\begin{array}{l}\text { A map/description of a path } \\
\text { through different places }\end{array}$ & $\begin{array}{l}\text { Character controller (first- } \\
\text { person or third-person } \\
\text { player); change of viewpoints }\end{array}$ & $\begin{array}{l}\text { Unity3D; } \\
\text { HTC Vive }\end{array}$ \\
\hline 6) & Interaction & $\begin{array}{l}\text { Actions/interaction with the } \\
\text { object }\end{array}$ & $\begin{array}{l}\text { UI (User Interface), animation } \\
\text { system }\end{array}$ & Unity3D \\
\hline 7) & Emotions & $\begin{array}{l}\text { Atmosphere of the architectural } \\
\text { space, family members' } \\
\text { emotions }\end{array}$ & $\begin{array}{l}\text { The simulation the VR can } \\
\text { provide - multi-sensory } \\
\text { experience: the collaboration } \\
\text { of all the systems in Unity3D }\end{array}$ & Unity3D \\
\hline
\end{tabular}

The games engine (Unity3D) represents different aspects of data: the architecture as objects, the material/texture as shading and material systems, the weather as the particle system, the movement as a first-person character, and the chronological narration as the UI which shifts between scenes (see Figure 6). Regarding the UI design, the system allows the user to have an interaction with specific objects, for example open/close the door, and an 'examining' feature enables the users to select and interact with the object, for example pick up a photo and rotate it (see Figure 7). Moreover, a note system is embedded in the examining system in which the users who are not familiar with the family's story can obtain separate items of information attached to the interactive 
objects. Accordingly, the users would find different ways to learn about the history of this family.
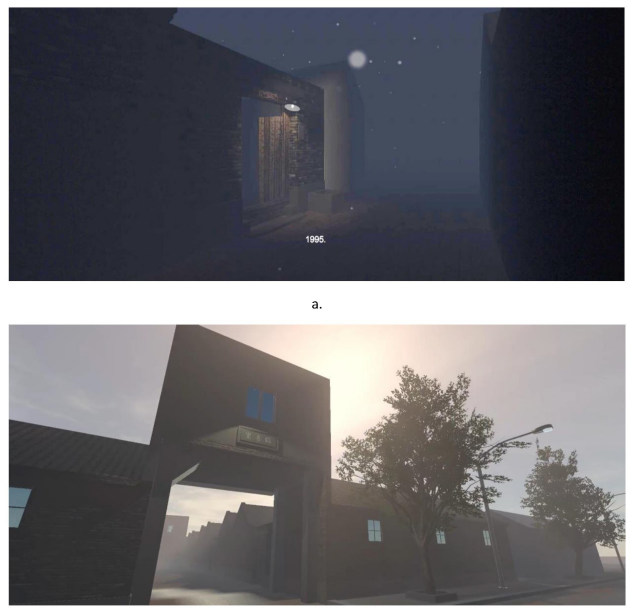

b.

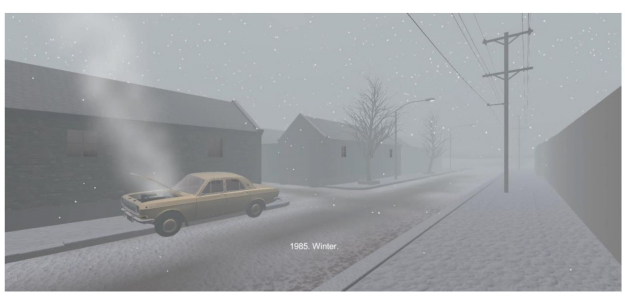

Haptic and olfactory feelings need to be suitably implemented. For haptic feelings, the nature of th $\mathrm{e}$ interaction has been changed from freely touching and interact with objects to using a keyboard and mouse, or headset and controllers. Actual collision with objects is no longer a feature but can be visually (not physically) imitated in the VR system. However, how to create this feedback as counterforces to the users and keep the consistency regarding the locations of the real and virtual objects need further developmental work.

Olfactory senses are a powerful agent in the recollection of memory (Barbara and Anthony, 2006).
However, establishing how to re-create this complex mechanism without causing unhelpful distraction is challenging for the project, even if this is still a peripheral aim at this stage. Table 2 proposes the potential strategy for the re-creation of these two senses; this still needs further work.

The representation of emotion in the VR experience represents another challenge. The understanding of the same adjective could be different depending on the context. The system should aim to objectively represent the atmosphere according to the description through the interaction between different functions (systems) in Unity3D. However, some variance in interpretation is still inevitable, especially when dealing with metaphorical phrases.

For example, an expression like "I was feeling blue" does not indicate any real colour, it rather indicates that the person was sad or depressed. Although it is not an obscure metaphor, in the case of digital translation, everything needs a "value." Therefore, the interpretation of this expression could be in danger of overinterpretation or misinterpretation. In Figure 6, the atmosphere of every scene is represented according to different emotions:

1. the first scene was derived from a piece of childhood memory - "a haunting and gloomy alley."

2. the second scene tries to translate the expression of "the sky of the city was always grey, so was my mood."

3. the third scene shows the expression of "it was an extremely cold winter, the street was quiet and cheerless."

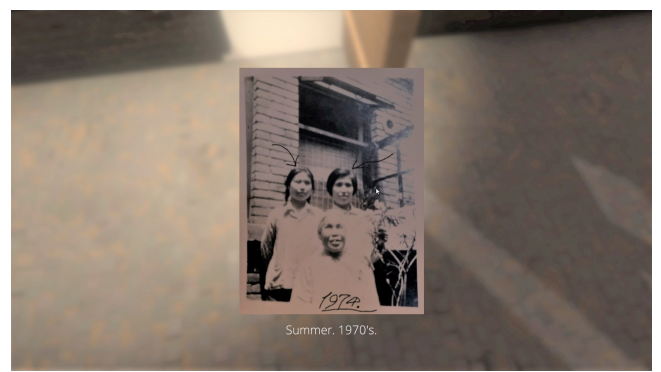

Figure 6

Three scenes of the home in 1995 (a), 1950 (b) and 1985 (c).

Figure 7

The user can examine and rotate an object and annotation is also provided by the system with background information. The background is blurred to make the object the dominant visual item. 
To mitigate this effect, further information is collected after participants experienced the VR system. This aims to gather feedback from the users to test to what extent the emotions re-emerged in the experience. This will be discussed in the results section later.

\section{Model Test and Results}

The family members were invited to experience the system. This was screen based rather than a fully immersive headset system, partly because many of the participants are from fifty to eighty years old. This means there are increased health and safety and therefore the headset was not used in this preliminary study.

The analysis of the feedback from the participants, and observations of behaviour, indicate the following:

- the immersive visual experience was sometimes unstable.

- participants preferred staying together as a group rather than experiencing the system individually.

- ambient noise and similar external distraction tended to interfere with the sense of immersion.

- regarding a sense of immersion, the participants generally felt that the VE looked too "tidy" to them.

- the atmosphere roughly fits the subjects' expectation but was not regarded as completely "accurate"

Arising from the initial analysis some observations can be made:

It is possible that with the screen-based system in particular, sound effects could be a significant factor to maintain or enhance the immersion. This could be especially true if they hear a context-appropriate familiar sound such as radio and season-related environmental sounds.

It is clear that the quality of the texturing and models in the VR needs to be enhanced to obtain a more "realistic" experience where the narrative is better reflected in the VE. The comments about how the environment looked too 'tidy' is recognised from other research. An absence of 'the other' is a known issue in terms of sense of immersion; addressing this is a particular challenge.

\section{Case Study Conclusion}

The system was broadly successful as a workflow from memories to a visualised VR, with continuous engagement of the participants. The set-up of the world would become increasingly detailed and flexible to encompass different versions of memories. Moreover, continually pursuing answers about the architectural details can lead the participants to try to sketch out pictures and this does not always relate to the participants' profession. Based on the initial feedback from the participants, the VR experience does not fully re-create their memories because of the hard-edged digital objects and the lack of complexity in the real scenario. This gives motivation to further develop the virtual environment and increase the level of immersion, with the ideal to reach a level of "entrancement" (Ryan 2003).

This process is still based on a broadly linear approach. As such it does not allow the participants to "change" the memory and create an alternative reality. However, in general terms this case study has helped develop and validate a system to move from "text" (memory as text) to VR. In the subsequent case study of this project, Umberto Eco's The Name of the Rose will be used as the narrative. Here we can investigate how to deal with the multiple versions of a real environment and how to accommodate them within a serious game environment.

\section{REFLECTIONS}

We began the paper looking at work from around 20 years ago. The nature of developments the intervening period has made it apparent that the contemporary digital sketch may bear little resemblance to the conventional digital sketch. The increasingly sophisticated and capable digitally mediated environment that we have today has created the possibility 
of more abstract and conceptual instantiations of the 'sketch'. This paper has described current research that investigates and explores such alternative ideas.

Interestingly Rattenbury (2017) has examined the work of famous English author, Thomas Hardy, who also had a career as architect. In his novel Far from the Madding Crowd, Hardy invented a county of Wessex, and invented an imaginary world, populated with architecture and landscape, that gained an important place in popular culture. Rattenbury noted that Hardy 'started developing Wessex as though it were an architectural project'. In fact what he did was to make architectural drawings and sketches of the buildings, elevations, partial interiors and so on, so that when he came to write, the drawn sketch became the scene that he was able to write the narrative against. His architectural sketch was a kind of stage set.

This is an interesting reversal of the main idea in this paper; for Hardy it is a sketch becoming the narrative. But it illustrates the important idea that the narrative and the sketch can have an important interplay and symbiotic relationship in the creation of one, or the other, or both.

\section{REFERENCES}

Barbara, A and Anthony, P 2006, Invisible Architecture: Experiencing Places through the Sense of Smell, Skira, Milan

Bassanino, M. N. and Brown, A.G.P. 1999 'Computer Generated Architectural Images: A Comparative Study', eCAADe Conference Proceedings,15-17 September 1999,, Liverpool (UK) , pp. pp. 552-556

Brown, A.G.P 2002 'CAAD Complements: Art and Science, Connecting the Real and the Virtual', 20th eCAADe Conference Proceedings, Warsaw (Poland), pp. pp. 214-218

Brown, A.G.P. and Lee, H.R. 2000 'A mental space model: towards computer augmented design', Greenwich 2000: Digital Creativity Symposium, Greenwich, London, pp. pp. 214-218

Calvino, I 1997, Invisible Cities, Vintage, London

Coughlan, T and Johnson, P 2006 'Interaction in creative tasks', Proceedings of the 2006 Conference on Human Factors in Computing Systems, Montréal, Québec, Canada, pp. 531-540
Eco, Umberto 1992, Interpretation and Overinterpretation, The Press Syndicate of the University of Cambridge, Cambridge

Hannibal, C, Brown, AGP and Knight, M 2004 'How Useful is the Digital Sketch? Architecture in the Network Society', 22nd eCAADe Conference Proceedings / ISBN 0-9541183-2-4, Copenhagen, pp. 374-379

Hannibal, C, Brown, AGP and Knight, M 2005, 'An assessment of the effectiveness of sketch representations in early stage digital design', International Journal of Architectural Computing, 3(1), pp. 107-126

Miller, JH 2002, On Literature, Routledge, London

Nell, V 1988, Lost in a Book: The Psychology of Reading for Pleasure, Yale University Press

Rattenbury, K 2017, The Wessex Project: Thomas Hardy, Architect, Lund Humphries Publishers Ltd

Ritchie, I 2014, Being and Architect, Royal Acdemy Publications, London

Ryan, ML 2003, Narrative as Virtual Reality: Immersion and Interactivity in Literature and Electronic Media, Johns Hopkins University Press

Webb, N and Brown, A.G.P 2010, 'Examination of the Designs by Auguste Perret Using Digitally-Enabled Forensic Techniques', International Journal of Architectural Computing, vol. 8 - no. 4 , p. 537 